\title{
Amperometric Biochemical Characterization of Isolated Fungal Strains
}

\author{
Sreenath Subrahmanyam, ${ }^{*+,+++++}$ Narendran Kodandapani,${ }^{++}$J. N. Ahamarshan, ${ }^{++}{ }^{++}$Balu Ranganathan, ${ }^{+}$ \\ Kumaran Shanmugam, ${ }^{+}$D. Jeyakumar, ${ }^{++++}$and T. V. Subramanian ${ }^{+}$ \\ $+\quad$ Department of Chemical Engineering, A.C. College of Technology, Anna University, Madras, India \\ ++ Center for Ecological Science, Indian Institute of Science, Bangalore, India \\ ++ Center for Biotechnology, A.C. College of Technology, Anna University, Madras, India \\ ++++ Electrodics and Electrocatalysis Division, Central Electrochemical Research Institute (CECRI), Karaikudi, India \\ ${ }^{++++}$Present address: Institute of BioScience and Technology, Cranfield University at Silsoe, Silsoe, MK 45 4DT, UK \\ e-mail: sri@cranfield.ac.uk; website: www.silsoe.cranfield.ac.uk/biotech
}

\begin{abstract}
The identification and biochemical characterization of microbial species by electrochemical methods have helped to develop microbial sensors that are rapid and effective. In this article, we present results of biochemical characterization of five fungi, the assimilation and biochemical characterization of various substrates and tolerance to selected inhibitors. The results are based on the respiratory rate and assimilatory profile of these fungi and are more rapid and reliable. The experimental results are discussed here with reference to individual fungus. Further, the advantages of the electrochemical assimilation for the biochemical characterization of the microbes have been discussed.
\end{abstract}

Keywords: Biochemical characterization, Fungi, Biosensor, Electrochemical assimilation, Amperometry

\section{Introduction}

A detailed investigation on the biochemical characteristics of the microorganisms under study is necessary to develop a biosensor for enhanced stability and selectivity. Microbial sensors for monitoring various pollutants have been developed [1], where the microorganisms are in direct contact with a transducer, converting the biochemical signal into an electrical response [2-6]. Microbial sensors comprising immobilized whole cells and an oxygen probe have been used for determination of assimilable sugars [7], acetic acid [8], alcohol [9], vitamins, antibiotics, peptides, enzyme activities, biochemical oxygen demand, cofactors, inhibitors for measurement of enzyme activities, and for determination of glutamic acid, based on the decarboxylation of glutamic acid by glutamate decarboxylase by measuring carbon dioxide produced, using carbon dioxide gas sensing probe [10]. Assimilation characteristics of various microorganisms such as molds, yeasts, bacteria, and actinomycetes have been tested with various substrates. Key metabolites or the rate of their overall metabolic reactions ATP, NADH, cytochrome content and DNA are suitable for describing the physiological state [11-18].

There have been reports on simultaneous measurement of two parameters, the content of proteins and nucleic acids and the determination of complex variables like biodegradable compounds and mutagenic substances in wastewater. It also has been found that a very low microbial loading of the biosensor is a prerequisite for a kinetically controlled respiration electrode and such sensors coupled with suitable immobilization of the microorganisms as well as thin membranes have to be used. The sensitivity of this type of sensor is mainly determined by the cell activity but not by diffusion limitation and the advantage is that one could attain response times of about $15 \mathrm{~s}$ by very low 'microbe loading' of the sensor [19-23]. In this article, we present the results of bioelectrochemical characterization of five fungi that have been isolated from areas where polyurethane wastes are dumped. The technique that employs an electrochemical probe for study of biochemical characterization has many advantages to the conventional biochemical characterization that is studied based on the appearance of a 'zone of inhibition' on the microbial growth plates. The organisms' potential to assimilate alcohols, carbohydrates, organic acids, amino acids, and their resistance to heavy metals and antibiotics have been discussed.

\section{Materials and Methods}

\subsection{Materials}

Potassium dihydrogen orthophosphate (AR grade) was purchased from Ranbaxy Laboratories, Bombay, India and all the other chemicals were purchased from Loba Chemie (AR grade) Bombay, India. All the analyses were done using Millipore water (deionized). Nitrocellulose membrane, (pore size $0.22 \mu \mathrm{m}$ diameter) was purchased from Bioanalytical Systems Inc. USA.

\subsection{Isolation and Identification of Fungi}

The fungi were isolated from a polyurethane manufacturing industry in Vellore, India. These were identified at mycology division, Indian Agricultural Research Institute, Pusa, New Delhi, India. The names of the identified fungi are Aspergillus niger, Aspergillus terrues, Fusarium oxysporum, Fusarium solani and Fusarium tamerii.

\subsection{Culture of Fungi}

The fungi were cultured on $12 \mathrm{~mL}$ of the slant culture medium in the test tube of size $15 \mathrm{~mm} \times 160 \mathrm{~mm}$ at $27^{\circ} \mathrm{C}$ for 2 days prior 
to assimilation tests. The fungi were grown in Czapek-Dox media $\left[\mathrm{KH}_{2} \mathrm{PO}_{4}(1 \mathrm{~g}), \mathrm{NaNO}_{3}(2 \mathrm{~g}), \mathrm{MgSO}_{4}(0.5 \mathrm{~g}), \mathrm{KCl}(0.5 \mathrm{~g}), \mathrm{FeSO}_{4}\right.$ $(0.01 \mathrm{~g})$, sucrose $(30 \mathrm{~g})$ and agar $(15 \mathrm{~g})$ in 1 liter of distilled water at $\mathrm{pH}$ 7.2].

\subsection{Fabrication of the Oxygen Electrode}

A dissolved oxygen (DO) probe was fabricated using a gold cathode (area $0.03 \mathrm{~cm}^{2}$ ), a platinum counter electrode and a $\mathrm{Ag} / \mathrm{AgCl}$ reference electrode. The gas permeable membrane used in the probe was purchased from Century Instruments Co., Chandigarh, India. The electrochemical probe employed for the studies on assimilation and biochemical characterization, was fabricated by coupling the immobilized membrane with the DO probe with the aid of dialysis tube. A Wenking potentiostat (model POS 88, Japan) was used with a Rikadenki $X-Y-t$ recorder (Japan).

\subsection{Assembly of the Fungal Electrode}

The fungi sensor fabricated for assimilation tests is given in Figure 1. Nitrocellulose membrane (pore size $<0.25 \mu \mathrm{m}$ ) procured from Millipore company was used as the matrix for immobilization. The fungi were immobilized by physisorption, after which the membrane was washed thoroughly with phosphate buffer ( $\mathrm{pH} 7.2$, conc. $100 \mathrm{mM}$ at a temperature of $27^{\circ} \mathrm{C}$ ) to remove the loosely bound fungi on the membrane. A fungal dispersion (harvested during stationary growth phase) containing $0.2 \mathrm{~g}$ of wet weight of the fungus $/ \mathrm{cm}^{3}$ was used for immobilization. The membrane retaining the fungus was placed on the Teflon membrane of the oxygen electrode so that the fungi were trapped between the two membranes. The membranes were covered with a nylon net and fastened with rubber rings. The immobilized membranes were stored at $4{ }^{\circ} \mathrm{C}$ in phosphate buffer (pH 7.2, conc. $100 \mathrm{mM}$ ) when not in use

\subsection{Calculation of Oxygen Reduction Current}

The oxygen reduction current $(I)$ of the assembled sensor was obtained by applying a potential of $-0.6 \mathrm{~V}$ to the gold cathode with reference to $\mathrm{Ag}-\mathrm{AgCl}$ electrode. The solution was stirred

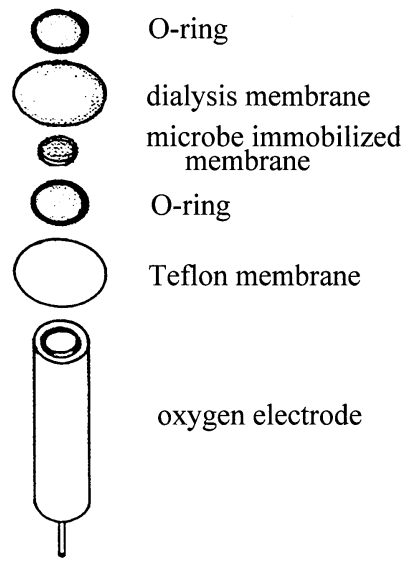

Fig. 1. Fabrication of the microbial electrode as described by Karube and Suzuki has been used [26]. and the current was recorded as steady-state current $\left(I_{\mathrm{s}}\right)$, after the addition of the analyte, a new steady state is now obtained $\left(I_{\mathrm{b}}\right)$ which is recorded. The change in the oxygen reduction current $(\Delta I)$, was calculated as $\left(\Delta I=I_{\mathrm{b}}-I_{\mathrm{s}}\right)$.

\section{Results and Discussion}

\subsection{Principle of Assimilation and Response of the Fungal Electrode}

The initial current at zero time $\left(i_{0}\right)$ was obtained with buffer solution saturated with DO, which indirectly shows the endogenous respiration of the fungi. The substrate was injected into the system and permeated through the porous nitrocellulose membrane, prior to being assimilated by the immobilized fungi. The enhanced assimilation results in increase in the respiratory activity of the fungi resulting in a decrease of DO at the fungal membrane/dissolved oxygen sensor interface. Hence, the current of the electrode decreased markedly with time until a steady state was reached since the respiration of the fungi was activated. The steady state indicated the diffusion of $\mathrm{O}_{2}$ from a sample solution and that the $\mathrm{O}_{2}$ consumption by fungi is in equilibrium. The steady-state current depends on numerous factors such as concentration of substrate, the assimilation activity of the immobilized fungi and the rate of metabolism of substrate.

\subsection{Results on Assimilation of Substrates}

The assimilation of amino acids, carbohydrates, organic acids and alcohols were studied for the fungi. Heavy metals and

Table 1. Electrochemical measurement of assimilation of amino acids by isolated fungi, concentration of amino acids, $2 \mathrm{mg} / \mathrm{mL}$, in $\mathrm{pH} 7.2$, $100 \mathrm{mM}$, temperature $27^{\circ} \mathrm{C}$. Values show the oxygen reduction current as explained in Section 2.6. Results shown are average of three measurements.

\begin{tabular}{lrrrrr}
\hline \multicolumn{5}{c}{ Fungi } & \multicolumn{5}{l}{} \\
\cline { 2 - 6 } Substrates & $\begin{array}{l}\text { Fusarium } \\
\text { solani }\end{array}$ & $\begin{array}{l}\text { Fusarium } \\
\text { oxysporum }\end{array}$ & $\begin{array}{l}\text { Fusarium } \\
\text { tamerii }\end{array}$ & A. niger & A. terreus \\
\hline Amino Acids & & & & & \\
DL-Alanine & 213 & 20 & 60 & 8 & 80 \\
DL-2-Amino-n- & 213 & 5 & - & - & - \\
$\quad$ butyric acid & & & & & \\
L-Arginine HCl & 26 & 8 & 40 & 2 & 100 \\
DL-Aspartic acid & 186 & 10 & 53 & 4 & 66 \\
L-Cysteine & - & 5 & 26 & - & 33 \\
L-Glutamic acid & 79 & 5 & 32 & 4 & 60 \\
Glycine & 106 & 10 & 24 & - & 60 \\
Histidine HCl & 53 & 5 & 16 & 4 & 60 \\
DL-Isoleuceine & 106 & 5 & 16 & 4 & 100 \\
L-Leuceine & 106 & 7 & 40 & 4 & 60 \\
L-Lysine HCl & 26 & 2 & 12 & 4 & 40 \\
DL-Methionine & 79 & 5 & 10 & 2 & 100 \\
DL-B Phenyl- & 373 & 6 & 30 & - & 360 \\
alanine & & & & & \\
L-Proline & 186 & 4 & 60 & - & 200 \\
DL-Serine & 79 & 7 & 64 & 2 & 150 \\
DL-Threonine & 106 & 6 & 24 & 6 & 150 \\
DL-Tryptophan & 26 & - & 30 & 4 & 50 \\
L-Tyrosine & 106 & 7 & 50 & 2 & 300 \\
DL-Valine & 79 & 7 & 20 & 6 & 350 \\
\hline & & & & & \\
\hline
\end{tabular}


antibiotics were studied for their inhibitory concentrations. Results of electrochemical measurement of assimilation of amino acids are presented in Table 1. Though sucrose was used in the media, glucose was used as the standard substrate for all the organisms, because assimilation studies for different microbes by various groups have been performed with glucose as a standard substrate and it is hence easy to compare the results. Fusarium solani showed the highest response among the fungi studied. The assimilation of glucose was found to be lower, as seen from the $\Delta I$ values recorded for Aspergillus niger. The other fungi recorded good responses for glucose. These results showed that the oxygen consumption varied among the fungi. Fusarium solani had excellent responses for all the amino acids, however, the fungus could not assimilate ornithine $\mathrm{HCl}$, even at concentrations of $5 \mathrm{ppm}$. Aspergillus niger was not able to assimilate DL- $\beta$ phenyl alanine and L-proline at concentrations of $2 \mathrm{ppm}$ and $1 \mathrm{ppm}$, respectively. Aspergillus terreus showed good signals for all the amino acids except for DL-2-amino- $n$-butyric acid. In general none of the fungus studied had an unusually high assimilation for any of the amino acids studied.

Table 2. Electrochemical measurement of assimilation of alcohols, organic acids and carbohydrates by isolated fungi. Substrate concentration at the time of injection onto the fungal electrode was $2 \mathrm{mg} / \mathrm{mL}$, in $\mathrm{pH} 7.2,100 \mathrm{mM}$, temperature $27^{\circ} \mathrm{C}$ (Section 2.6). Results shown are average of three measurements.

\begin{tabular}{|c|c|c|c|c|c|}
\hline \multirow[b]{2}{*}{ Substrates } & \multicolumn{5}{|l|}{ Fungi } \\
\hline & $\begin{array}{l}\text { Fusarium } \\
\text { solani }\end{array}$ & $\begin{array}{l}\text { Fusarium } \\
\text { oxysporum }\end{array}$ & $\begin{array}{l}\text { Fusarium } \\
\text { tamerii }\end{array}$ & A. niger & A. terreus \\
\hline \multicolumn{6}{|l|}{ Organic acids } \\
\hline Fumaric acid & 133 & 8 & 24 & 4 & - \\
\hline Citric acid & 33 & 6 & 16 & - & - \\
\hline Acetic acid & 333 & 20 & 120 & 25 & 260 \\
\hline Lactic acid & 233 & 20 & 70 & 25 & 140 \\
\hline Maleic acid & - & 5 & - & 5 & - \\
\hline Tartaric acid & 26 & 20 & - & 6 & - \\
\hline Ascorbic acid & 33 & 13 & 10 & 4 & 60 \\
\hline Formic acid & 39 & 10 & 30 & 10 & 325 \\
\hline \multicolumn{6}{|l|}{ Alcohols } \\
\hline Methyl alcohol & 166 & 25 & 20 & 15 & 10 \\
\hline Ethyl alcohol & 233 & 40 & 60 & 480 & 60 \\
\hline Propyl alcohol & 99 & 20 & 60 & 5 & 10 \\
\hline Isobutyl alcohol & - & 50 & 80 & 50 & 70 \\
\hline Isoamyl alcohol & - & 50 & 40 & 35 & 130 \\
\hline Sorbitol & - & - & 140 & - & - \\
\hline Mannitol & 133 & 10 & 40 & 25 & 30 \\
\hline Glycerol & - & 30 & 40 & 10 & - \\
\hline \multicolumn{6}{|l|}{ Carbohydrates } \\
\hline Glucose & 46 & 214 & 360 & 120 & 300 \\
\hline D-Mannose & 79 & 100 & 60 & - & 50 \\
\hline D-Maltose & 6 & 20 & 30 & 40 & 50 \\
\hline Sucrose & 126 & 150 & 40 & 25 & 100 \\
\hline Lactose & - & - & - & - & - \\
\hline D-Arabinose & 53 & 50 & 4 & 20 & 25 \\
\hline Raffinose & 39 & - & 4 & 25 & 40 \\
\hline D-Fructose & 26 & 50 & 15 & 40 & 60 \\
\hline L-Arabinose & 33 & 50 & 10 & 60 & - \\
\hline Trehalose & 53 & 10 & 5 & 25 & 20 \\
\hline Cellobiose & 26 & 15 & 25 & 25 & 20 \\
\hline D-Galactose & 33 & 50 & 25 & 25 & 25 \\
\hline D-Melibiose & 39 & - & 40 & 50 & 50 \\
\hline Dextrose & 159 & 20 & 20 & 75 & 75 \\
\hline
\end{tabular}

Table 2 presents electrochemical a measurement of assimilation of alcohols, organic acids and carbohydrates. As expected none of the fungi was able to assimilate lactose, however, surprisingly, a very weak signal was obtained for Fusarium tamerii confirming the assimilation of lactose at a concentration of $20 \mathrm{ppm}$. Even a lactose concentration as low as $4 \mathrm{ppm}$ was high for assimilation by Aspergillus niger. It is worth mentioning that lactose as a substrate is very difficult to be assimilated by organisms. Fusarium solani showed best responses to carbohydrates. Aspergillus niger was not able to assimilate D-melibiose at low concentrations and weak responses were obtained for other fungi. Aspergillus terreus could not assimilate L-arabinose. Fusarium oxysporum and Aspergillus niger were able to assimilate malic acid, but only weak signals were obtained by these two fungi confirming low levels of assimilation. Fusarium solani, and Aspergillus niger showed good responses to acetic acid and alcohol, respectively, and hence they were successfully exploited for the development of microbial sensors [24, 25].

\subsection{Results on Response on Inhibitory Concentrations of Selected Heavy Metals and Antibiotics}

Table 3 presents the response for inhibitory concentrations of selected heavy metals and antibiotics. Aspergillus niger and Aspergillus tamerii showed better resistance to selected heavy metals and antibiotics in relation to the other fungi studied. Fusarium solani, Fusarium tamerii and Aspergillus terreus, had high resistance of $30 \mathrm{ppm}$ for cadmium. Aspergillus terreus had a very high resistance of $80 \mathrm{ppm}$ for cobalt. All the fungi studied, showed low resistance to mercury, with maximum resistance shown by Fusarium oxysporum. Fusarium tamerii had a resistance as high as $90 \mathrm{ppm}$ for lead. Fusarium solani had high resistance to mercury with $50 \mathrm{ppm}$ as concentration.

Table 3. Electrochemical measurement of resistance of fungi to heavy metals and antibiotics. Stock solution of substrate concentration was $200 \mathrm{ppm}$, in $\mathrm{pH} 7.2,100 \mathrm{mM}$, temperature $27^{\circ} \mathrm{C}$ (Section 2.6). Results shown are average of three measurements.

\begin{tabular}{|c|c|c|c|c|c|}
\hline & \multicolumn{5}{|l|}{ Fungi } \\
\hline & $\begin{array}{l}\text { Fusarium } \\
\text { solani }\end{array}$ & $\begin{array}{l}\text { Fusarium } \\
\text { oxysporum }\end{array}$ & $\begin{array}{l}\text { Fusarium } \\
\text { tamerii }\end{array}$ & A. niger & A. terreus \\
\hline \multicolumn{6}{|l|}{ Heavy metals } \\
\hline Cadmium & 30 & - & 30 & 11 & 30 \\
\hline Cobalt & 10 & 40 & 60 & 20 & 80 \\
\hline Manganese & 20 & 40 & 40 & 30 & 60 \\
\hline Strontium & 220 & 40 & 40 & 30 & 13 \\
\hline Nickel & 50 & 20 & 40 & 30 & 80 \\
\hline Zinc & - & - & - & - & 30 \\
\hline Copper & 30 & 50 & 50 & 50 & 40 \\
\hline Chromium & - & 20 & 40 & 60 & 90 \\
\hline Iron & 40 & 20 & 60 & 40 & 20 \\
\hline Mercury & 20 & 30 & 20 & 10 & 10 \\
\hline Lead & - & - & 90 & 40 & 20 \\
\hline Magnesium & 50 & 60 & - & - & - \\
\hline \multicolumn{6}{|l|}{ Antibiotics } \\
\hline Gryseofulvin & 15 & 3 & 14 & 3 & 21 \\
\hline Mycoderm & 12 & 8 & 19 & 6 & 16 \\
\hline Clotrimixozole & 3 & 4 & 15 & 9 & 12 \\
\hline Ketagonazole & 3 & 3 & 5 & 3 & 8 \\
\hline
\end{tabular}


Table 4. C represents the results obtained by conventional technique, S represents the results obtained by electrochemical assimilation technique. Comparison between the data by conventional technique obtained by studying the 'zone of inhibition in plates' and the data obtained by electrochemical assimilation technique. Concentration of substrates used for study was $2 \mathrm{mg} / \mathrm{mL}$, media used for fungal growth during this experiment was Czapek-Dox, the composition of which is mentioned in Section 2.3. ++ : very positive, $+:$ positive, $-:$ negative, $\mathrm{D}+$ : delayed positive response, $\mathrm{W}$ : weak positive response, $\mathrm{D}-$ : delayed negative response, +- : variable response, $\mathrm{X}$ : result not available.

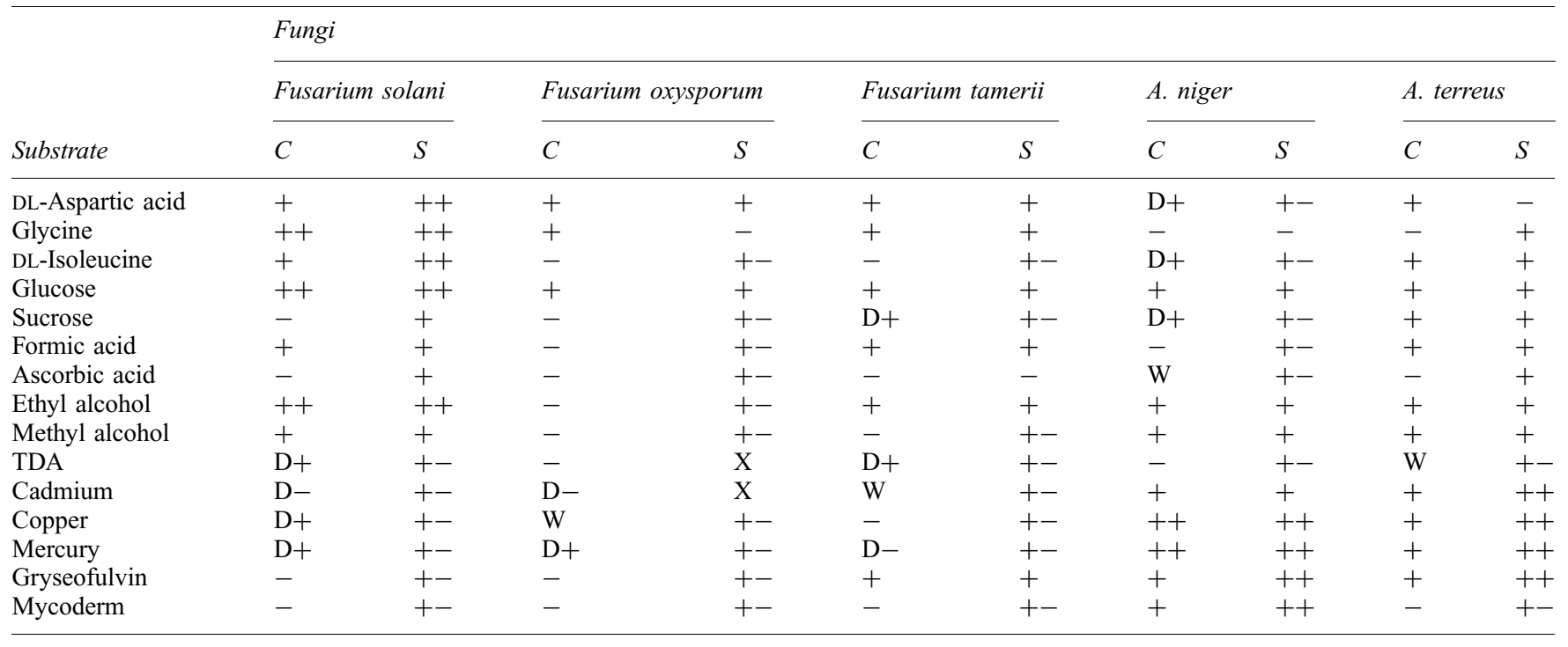

Aspergillus terreus showed good resistance of $21 \mathrm{ppm}$ for gryseofulvin and $16 \mathrm{ppm}$ for mycoderm. A high resistance of $19 \mathrm{ppm}$ of mycoderm and $15 \mathrm{ppm}$ of clotrimixozole was recorded for Fusarium tamerii. Aspergillus terreus showed $8 \mathrm{ppm}$ as maximum resistance limit for ketagonazole. In summary, none of the fungi showed remarkable resistance to inhibitory concentrations of either heavy metals or antibiotics.

\subsection{Comparison Between Results of Substrate Assimilation by Electrochemical Method and Conventional Method}

Results of the substrate assimilation by 'electrochemical assimilation technique' were compared with conventional result obtained by studying the 'zone of inhibition on plates' (Table 4). The results obtained by the 'electrochemical assimilation technique', were similar to that obtained using the conventional method (zone of inhibition in plates), However, small differences in the results could be attributed to the fact that conventional technique gives only slow rates of assimilation by the fungi, and the 'amperometric technique' is fast and registers changes in the oxygen consumption during a very short time. Fusarium solani showed good response for alcohols, and $\Delta I$ value for ethanol was found to be very high among the alcohols in particular. Aspergillus terreus was not able to assimilate mannitol and others showed only a feeble response. All the interpretation of the values for resistance and inhibitory concentrations are based on the definition mentioned here. Resistance is the ability of the fungi to withstand the concentration of the antibiotic or heavy metal under study and thrive on substrate. This differs from one fungal strain to the other. Inhibitory concentration is the minimal concentration of the antibiotic or heavy metal that would inhibit the growth of the fungi. Readers are reminded that there are a number of definitions for these two terms and these cannot be used interchangeably.

\subsection{Optimization of $\mathrm{pH}$ and Temperature for Fungal Growth}

$\mathrm{pH}$ values and temperature for the growth of fungi were optimized using the same technique. The optimal temperature for Fusarium oxysporum and Aspergillus niger was found to be between 33 and $35^{\circ} \mathrm{C}$. Fusarium terreus had an optimum temperature of $27^{\circ} \mathrm{C}$ for growth. Aspergillus terreus and Fusarium solani show maximum assimilation of glucose between 28 and $32^{\circ} \mathrm{C}$ giving us the optimal temperature for growth of these fungi (Fig. 2). The optimal $\mathrm{pH}$ values for the growth of these fungi vary from $\mathrm{pH} 6$ to $\mathrm{pH} 8$, as can be seen in Figure 3 .

\section{Conclusions}

Biochemical characterization is mandatory for new microbial strains that are isolated. The conventional methods adopted are both, time-consuming and imprecise. The advantage of this method is that we can quantify the substrate assimilation to very

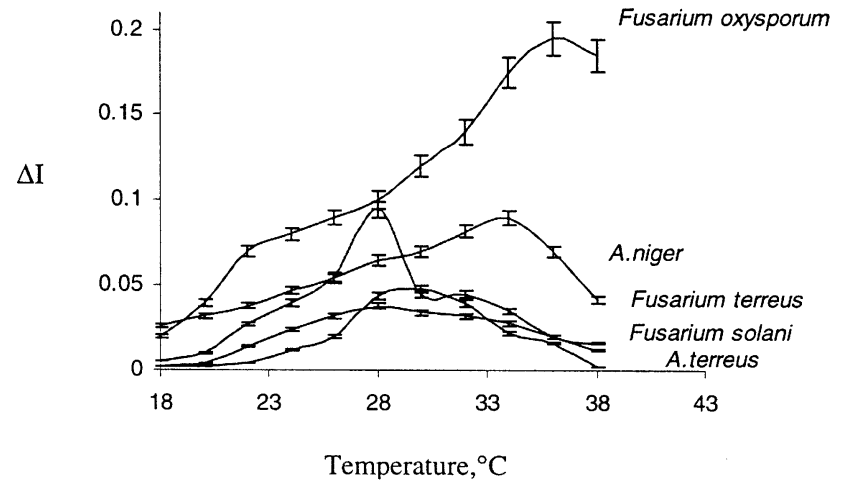

Fig. 2. Optimal temperature for the growth of the fungi, phosphate buffer $\mathrm{pH} 7.2$ was used, conc. $100 \mathrm{mM}$. 


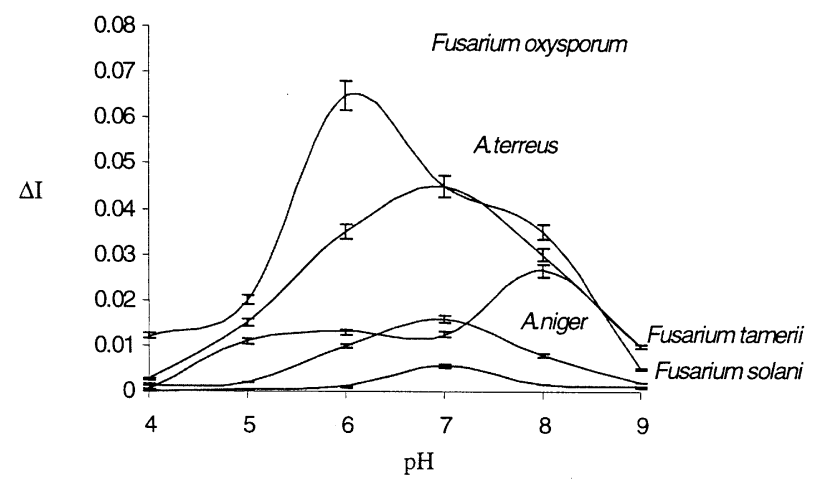

Fig. 3. Optimal $\mathrm{pH}$ for the growth of the fungi, phosphate buffer used, conc. $100 \mathrm{mM}$.

low levels that is either very difficult to achieve or in most cases impossible. That is one of the reasons why we believe that this method is more precise in comparison to conventional methods of biochemical characterization. We have endorsed the fact that biochemical characterization of microbes through rapid electrochemical methods using the amperometric principles is both sensitive and fast with an added advantage of its ability of quantitative registration at very low signals. Based on selective assimilation of the organisms, a potential organism for development of specific sensor could also be screened for further study, for example, Fusarium solani, and Aspergillus niger showed good responses to acetic acid and alcohol, respectively, and hence they were successfully exploited for the development of microbial sensors [24, 25]. These results could be used to compare different strains, mutant transformants of one and the same species.

\section{Acknowledgement}

SS thanks the Council of Scientific and Industrial Research, CSIR, Government of India, for a Senior Research Fellowship.

\section{References}

[1] K. Riedel, R. Renneberg, U. Wollenberger, G. Kaiser, F. Scheller, J. Chem. Technol. Biotechnol. 1989, 44, 85.

[2] K. Riedel, M. Kuhn, F. Scheller, Biophysics 1985, 107, 189.

[3] C.A. Corcoran, G.A. Rechnitz, Trends Biotechnol. 1985, 3, 92.

[4] U. Wollenberger, F. Scheller, P. Att, Anal. Lett. 1980, 13, 1201.

[5] R. Renneberg, K. Riedel, P. Liebs, F. Scheller, Anal. Lett. 1984, 17, 349.

[6] R. Renneberg, K. Riedel, F. Scheller, Appl. Microbiol. Biotechnol. 1985, 21, 180.

[7] M. Hikuma, H. Obana, T. Yasuda, Enzyme Microbiol. Technol. 1980, 2, 234.

[8] M. Hikuma, H. Suzuki, T. Yasuda, I. Karube, S. Suzuki, Eur. J. Appl. Microbiol. Biotechnol. 1979, 8, 289.

[9] M. Hikuma, T. Kubo, T.Y. Yasuda, I. Karube, S. Suzuki, Biotech. Bioeng. 1979, 21, 1845.

[10] S. Suzuki, I. Karube, Appl. Biochem. Bioeng. 1981, 3, 145.

[11] A. Heller, Current Opinion in Biotechnology 1996, 7, 50.

[12] J. Kathryn, S. Asala, M. Swarts, J.W. Anderegg, D.C. Johnson, Electroanalysis 2000, 12, 731.

[13] I.A. Borisov, A.V. Lobanov, A.N. Reshetilov, B.I. Kurganov, Prikl. Biokhim. Mikrobiol. 2000, 36, 254.

[14] A. Romani, M. Minunni, N. Mulinacci, P. Pinelli, F.F. Vincieri, M. Del Carlo, M. Mascini, J. Agric. Food. Chem. 2000, 48, 1197.

[15] A.P.F. Turner, Current Opinion in Biotechnology 1994, 5, 49.

[16] R.P. Baldwin, J. Pharm. Biomed. Anal. 1999, 19, 69.

[17] Yun-Ying Liao, Tse-Chuan Chou, Electroanalysis 2000, 12, 89.

[18] K. Stuik, Electroanalysis 2000, 12, 1, 55.

[19] I. Karube, Y. Nomura, Y. Arikawa, Trends Anal. Chem. 1995, 14, 295.

[20] H. Suzuki, E. Tamiya, I. Karube, Electroanalysis 1995, 6, 299.

[21] I. Karube, M. E. Sang Mok Chang, Biosensor Principles and Applications, Marcel Dekker Inc., New York 1994, p. 267.

[22] I. Karube, K. Yokoyama, Proc. NATO Advanced Research Workshop, Brixen, Italy 1993, 281.

[23] I. Karube, K. Yokoyama, Biotechnology Current Progress, 1992, 1.

[24] S. Subrahmanyam, K. Shanmugam, V.M. Madhav, M. Murugesan, T.V. Subramanian, D. Jeyakumar, Electroanalysis 2000, 12, 1051.

[25] S. Subrahmanyam, K. Shanmugam, M. Karunakaran, V.M. Madhav, T.V. Subramanian, D. Jeyakumar, Electroanalysis, in press.

[26] I. Karube, M. Suzuki, in Biosensors: A Practical Approach (Ed: A.E.G. Cass), 1990, 155. 